\title{
Clinical characteristics and predictors of 5-year survival among colorectal cancer patients in a tertiary hospital in Malaysia
}

\author{
Kean Ghee Lim $^{1}$, Chit Seng Lee ${ }^{1}$, Daniel Hong Jeng Chin ${ }^{1}$, Yong Song Ooi ${ }^{1}$, Sajesh K. Veettil ${ }^{2}$, \\ Siew Mooi Ching ${ }^{3}$, Ismail Abdul Sattar Burud ${ }^{1}$, Jasiah Zakaria ${ }^{4}$ \\ ${ }^{1}$ Clinical School, Department of Surgery, International Medical University, Jalan Rasah, Seremban, Negeri Sembilan, Malaysia; 'School of Pharmacy/ \\ School of Postgraduate Studies, International Medical University, Kuala Lumpur, Malaysia; ${ }^{3}$ Department of Family Medicine, Faculty of Medicine \\ and Health Sciences, University Putra Malaysia, Serdang, Malaysia; ${ }^{4}$ Department of Surgery, Hospital Tuanku Ja'afar Seremban, Negeri Sembilan, \\ Malaysia \\ Contributions: (I) Conception and design: KG Lim, CS Lee, DHJ Chin, YS Ooi, IAS Burud; (II) Administrative support: KG Lim, SK Veettil, SM \\ Ching, J Zakaria; (III) Provision of study materials or patients: J Zakaria; (IV) Collection and assembly of data: KG Lim, CS Lee, DHJ Chin, YS Ooi, \\ IAS Burud; (V) Data analysis and interpretation: All authors; (VI) Manuscript writing: All authors; (VII) Final approval of manuscript: All authors. \\ Correspondence to: Dr. Kean Ghee Lim, FRCS. Professor, Clinical Campus, International Medical University, Jalan Rasah, Seremban 70300, Malaysia. \\ Email: keanghee_lim@imu.edu.my.
}

Background: Colorectal cancer is the second most common cancer in Malaysia. Its disease burden is likely to increase over time owing to its current trends in this region. This study was undertaken to determine the 5-year survival rate and prognostic factors for survival in colorectal cancer patients treated in a tertiary hospital, in Malaysia.

Methods: We reviewed the records of colorectal cancer patients treated in Hospital Tuanku Ja'afar Seremban, Malaysia from 2008 to 2012. Survival analysis at five years was performed using the Kaplan-Meier method. Cox proportional hazard regression analysis was carried out to determine the predictors of 5 -year colorectal cancer survival.

Results: Of the 275 patients, $43.3 \%$ were colon cancers, $51.8 \%$ were rectal cancers. Only $2.2 \%$ were diagnosed in Stage I. 28.7\%, 33.1\%, and 16.7\% were in Stage II, III and IV respectively; 62/79 (78\%) of Stage II patients were in Stage III; $15.7 \%$ of patients were below the age of 50 and fewer of them presented early $(\mathrm{P}=0.002)$. The overall 5 -year survival was $46.5 \%$. It was $67.9 \%, 50.5 \%$ and $12.8 \%$ for Stage I\&II, III and IV patients respectively. Early stage of cancer $(\mathrm{P}<0.001)$ and age below the mean $(\mathrm{P}=0.01)$ were the most significant factor in predicting better survival. Gender and ethnic group were not associated with late presentation nor survival. Neither was there a difference between colon and rectum cancers nor patients who received elective surgical treatment compared to patients receiving other treatment first $(\mathrm{P}=0.085)$.

Conclusions: Late presentation is the most important predictor for poor outcome for colorectal cancer in Seremban. Patients under the age of 50 years present late more often, but do not have poorer survival.

Keywords: Colorectal neoplasms; staging; late presentation; Malaysia; survival rate

Submitted Oct 24, 2019. Accepted for publication Dec 17, 2019.

doi: 10.21037/jgo.2020.02.04

View this article at: http://dx.doi.org/10.21037/jgo.2020.02.04

\section{Introduction}

Globally, colorectal cancer is the third most commonly diagnosed cancer, with over 1.4 million new cases estimated to have occurred in 2012 (1). Colorectal cancer was believed to be less common in the Asian population compared to the Western population. However, there is an increasing trend in colorectal cancer incidence and mortality noticed in Asian countries, including Malaysia (1-3).

Colorectal cancer is the second most common cancer 
among both males and females in Malaysia with an agestandardized rate of 18.3 per 100,000 persons per year in $2012(1,4)$. The burden owing to colorectal cancer is likely to further increase over time in Malaysia due to its rapid urbanization and aging population $(4,5)$. The survival rate of patients with colorectal cancer is associated with the stage of the disease at presentation and it can be effectively increased with early diagnosis and appropriate treatment. However, most patients in Malaysia with colorectal cancer usually present at a late stage compared to the population in developed countries $(4,6,7)$. The overall 5 -year survival rate for patients with colorectal cancer in Malaysia has been reported to be between $34-60 \%$ depending on region (8-12). One selected group in Kuala Lumpur noted a 5 -year survival rate of $60.5 \%$ (12), while a report from Kelantan reported a 5 -year survival rate of $34.3 \%$ (9). The discrepancies in the 5-year survival rates are probably due to disparities in demographic and clinical characteristics of colorectal cancer patients at presentation, access to early diagnostic tests and treatment received in different settings.

However, there was a scarcity of studies that predict the association between demographic and clinical characteristics and treatment outcomes on the overall survival rate of colorectal cancer patients in developing regions in this country (13). There were no local studies on colorectal cancer survival outcomes from Negeri Sembilan (a developing state in Malaysia) available. Identifying the association between clinical characteristics and treatment outcomes on the overall survival rate is essential for early detection and improvement in cancer treatment. Therefore, we performed a study to determine the 5-year survival rate of colorectal cancer patients treated at Hospital Tuanku Ja'afar Seremban (HTJS), the tertiary hospital in Negeri Sembilan, Malaysia, from 2008 to 2012. In addition, we assessed the role of selected demographic, clinical and treatment factors in the prediction of the 5 -year survival rate among these patients.

\section{Methods}

All patients with a confirmed diagnosis of colorectal cancer seen at HTJS and entered into the National Cancer Patient Registry-Colorectal Cancer (NCPR-CC) between 2008 and 2012 were included. HTJS is one of 34 source data providers for the NCPR-CC. Inclusion was based on a diagnosis of colorectal cancer as defined by the International Classification of Disease Clinical Modification 9th edition (14). Patients who presented in 2008-2012 but were diagnosed earlier were excluded. All patients treated for colorectal cancer in HTJS were under the care of trained colorectal surgeons.

Data extracted from the NCPR-CC online database included socio-demographic and clinical data: such as age, sex, race, education level, smoking status, marital status, date and year of diagnosis, age at diagnosis, biopsy reports, American Joint Committee on Cancer (AJCC) staging (15), symptoms at presentation, anatomic site of the tumour, setting or initial treatment details, types of surgery performed, primary cause of death and survival duration. Hospital discharge records, histopathology and imaging reports were cross-checked where there was doubt in the consistency of information, especially in the staging in relation to survival or treatment received. Patients were followed-up until death or censored at the end of the study. Censored patients' National Registration Identity Card (NRIC) numbers were used to cross check with the data of the National Registration Department (NRD) for their vital status (whether still alive or dead).

Ethical clearance was obtained from the International Medical University Joint Committee and the National Medical Research and Ethics Committee. This study was registered under the National Medical Research Registry (NMRR-17-1380-36236 IIR). The authors are accountable for all aspects of the work in ensuring that questions related to the accuracy or integrity of any part of the work are appropriately investigated and resolved.

Data were analysed using SPSS, version 23 for Windows, (SPSS Inc., and Chicago, Illinois, USA). The level of significance was predetermined at 0.05 . Pearson's chi-squared test was used to demonstrate the association between variables, particularly between cancer staging and survival rate. Anova test was used to look for the significant association between the race and age. The cumulative survival and survival median were determined using the Kaplan-Meier survival curve. The Cox proportional hazard regression analysis was used to determine predictors for survival. Only independent variables with a $\mathrm{P}$ value less than 0.25 were included in the multiple Cox regression analysis (16).

\section{Results}

\section{Descriptive}

\section{Socio-demographic characteristics}

A total of 275 eligible patients with colorectal cancer reported 
in Hospital Tuanku Ja'afar from 2008 to 2012 were included in the analysis. The mean age $\pm \mathrm{SD}$ at diagnosis was $62.4 \pm$ 13.0 years $(\mathrm{n}=274)$. There were 163 men and 112 women (male: female $=1.47$ ) (Table 1). The vast majority of patients were from Negeri Sembilan, Malaysia. The proportion of Chinese (46.9\%), Malays (41.5\%) and Indians (11.3\%) reflect the racial composition of Negeri Sembilan (17) (Chinese 21.3\%, Malays 56.6\%, Indians 14\%) and the fact that the Chinese have a higher incidence of colorectal cancer. Only one patient was noted to be of different ethnicity, an Indonesian. For further analysis, he was grouped with Malays; $15.6 \%$ of the patients were under 50 -year-old, the age at which screening is usually advocated. The level of education of this cohort could not be determined in $>50 \%$, but the largest group had secondary level education.

\section{Clinical characteristics}

The location of cancer, the stage, and salient presenting features are shown in Table 2. Not all patients had the location of their tumours recorded (no record $=4.7 \%$ ), but slightly more than half of the patients had rectal tumours (51.8\%) compared to colonic tumours (43.3\%). Only 85 (30.9\%) patients presented with early cancer (stage I and II). In fact, only six (2.2\%) presented in stage I, and 62 of those in stage II were in stage IIb.

The prevalence of the most common symptoms recorded are listed in Table 2. In 40 patients there were no records of their symptoms on presentation. In the remaining 235 patients, at least one symptom was noted for each. Where a particular symptom is not recorded, it is considered absent. There were over 16 other symptoms recorded that were present in less than four individuals, such as jaundice, tenesmus, vomiting, and loss of appetite. These were not tabulated.

\section{Data verification}

In five cases, the stage of disease was revised due to errors noted in the registry data. This in effect decreased the number of patients in stage IV. However, it was noted that a few patients labelled as stage IV based on evidence of lung nodules noted on CT scan have survived for more than five years, with no evidence of changes on CT scan during follow-up. The stage of such patients was not altered for analysis, as such errors would occur in similar studies, especially when the radiology reports usually suggest they may be malignant.

Data regarding the type of initial management of 59 $(21.4 \%)$ patients were not available. Of the remaining,
Table 1 Socio-demographic characteristics, clinical characteristics and treatment of colorectal of colorectal cancer patients in Hospital Tuanku Ja'afar, Seremban 2008-2012

\begin{tabular}{|c|c|c|}
\hline & $\mathrm{n}=275$ & $\%$ \\
\hline \multicolumn{3}{|c|}{ Socio-demographic characteristics } \\
\hline \multicolumn{3}{|l|}{ Year presented } \\
\hline 2008 & 12 & 4.4 \\
\hline 2009 & 53 & 19.3 \\
\hline 2010 & 53 & 19.3 \\
\hline 2011 & 79 & 28.7 \\
\hline 2012 & 78 & 28.4 \\
\hline \multicolumn{3}{|l|}{ Gender } \\
\hline Male & 163 & 59.3 \\
\hline Female & 112 & 40.7 \\
\hline \multicolumn{3}{|l|}{ Ethnic groups } \\
\hline Chinese & 129 & 46.9 \\
\hline Malay & 114 & 41.5 \\
\hline Indian & 31 & 11.3 \\
\hline Others & 1 & 0.4 \\
\hline \multicolumn{3}{|l|}{ Age groups (years) } \\
\hline$\leq 39$ & 13 & 4.7 \\
\hline $40-49$ & 30 & 10.9 \\
\hline $50-59$ & 58 & 20.7 \\
\hline $60-69$ & 83 & 30.2 \\
\hline $70-79$ & 75 & 26.9 \\
\hline$\geq 80$ & 15 & 5.4 \\
\hline No record & 1 & 1.1 \\
\hline \multicolumn{3}{|l|}{ State domicile } \\
\hline Negeri Sembilan & 258 & 94.2 \\
\hline Melaka & 8 & 2.9 \\
\hline Other states & 5 & 1.9 \\
\hline No record & 2 & 0.7 \\
\hline \multicolumn{3}{|l|}{ Education level } \\
\hline None & 5 & 6.2 \\
\hline Primary & 26 & 9.5 \\
\hline Secondary & 47 & 17.2 \\
\hline Tertiary & 10 & 3.6 \\
\hline No record & 174 & 63.5 \\
\hline
\end{tabular}

Table 1 (continued) 
Table 1 (continued)

\begin{tabular}{|c|c|c|}
\hline & $n=275$ & $\%$ \\
\hline \multicolumn{3}{|l|}{ Marital status } \\
\hline Married & 145 & 52.7 \\
\hline Single & 12 & 4.4 \\
\hline No record & 118 & 42.9 \\
\hline \multicolumn{3}{|l|}{ Clinical characteristics } \\
\hline \multicolumn{3}{|l|}{ Site of tumour } \\
\hline Right colon & 42 & 15.6 \\
\hline Caecum & 16 & \\
\hline Ascending colon & 10 & \\
\hline Hepatic flexure & 3 & \\
\hline Transverse colon & 12 & \\
\hline Multiple & 1 & \\
\hline Left colon & 64 & 23.3 \\
\hline Splenic flexure & 3 & \\
\hline Descending colon & 11 & \\
\hline Sigmoid colon & 50 & \\
\hline Colon, unspecified & 12 & 4.4 \\
\hline Rectum & 144 & 51.8 \\
\hline Recto-sigmoid & 57 & \\
\hline Rectum & 85 & \\
\hline Anorectal & 2 & \\
\hline Not recorded & 13 & 4.7 \\
\hline \multicolumn{3}{|l|}{ AJCC staging } \\
\hline I & 6 & 2.2 \\
\hline$\| A$ & 17 & 6.2 \\
\hline IIB & 62 & 22.5 \\
\hline IIIA & 57 & 20.7 \\
\hline IIIB & 34 & 12.4 \\
\hline IV & 46 & 16.7 \\
\hline Not staged & 53 & 19.3 \\
\hline \multicolumn{3}{|c|}{ Symptoms at presentation ${ }^{a}$} \\
\hline Abdominal pain & $82 / 235$ & 34.9 \\
\hline Weight loss & $72 / 235$ & 30.6 \\
\hline Intestinal obstruction & $48 / 235$ & 20.4 \\
\hline Blood in stools & $103 / 235$ & 43.8 \\
\hline Altered bowel habit & $130 / 235$ & 55.3 \\
\hline
\end{tabular}

Table 1 (continued)
Table 1 (continued)

\begin{tabular}{|c|c|c|}
\hline & $\mathrm{n}=275$ & $\%$ \\
\hline \multicolumn{3}{|l|}{ Setting or type of initial } \\
\hline Emergency surgery & 19 & 6.9 \\
\hline \multicolumn{3}{|l|}{ Treatment } \\
\hline Elective surgery & 124 & 45.1 \\
\hline Neoadjuvant therapy & 39 & 14.2 \\
\hline Non-surgical palliative care & 11 & 4.0 \\
\hline Surgery setting not recorded & 23 & 8.4 \\
\hline No record & 59 & 21.5 \\
\hline \multicolumn{3}{|l|}{ Types of Surgery performed } \\
\hline Anterior resection & 69 & \\
\hline R hemicolectomy & 30 & \\
\hline Ap resection & 24 & \\
\hline Hartmann's procedure & 21 & \\
\hline Colostomy only & 15 & \\
\hline Subtotal colectomy & 8 & \\
\hline L hemicolectomy & 6 & \\
\hline Sigmoid colectomy & 4 & \\
\hline Ileostomy only & 2 & \\
\hline Local excision & 1 & \\
\hline Colonoscopic resection & 1 & \\
\hline Laparotomy & 2 & \\
\hline No surgery/No record & 92 & \\
\hline
\end{tabular}

${ }^{a}$ Denominator excludes those in whom there is no record.

19 needed emergency surgery that could not wait to be scheduled on an elective surgical list. Thirty-nine were scheduled for neoadjuvant therapy. Of the remainder, 124 $(45.1 \%)$ were operated on an elective surgery list and 11 had no record of surgery.

The types of operations performed were recorded in 183 (66.5\%) patients. Anterior resections, including low and ultra-low resections, were the commonest operations. Noncurative operations included colostomies, ileostomies, local excisions, and laparotomies.

\section{Analysis}

\section{Late presentation}

Table 2 shows the features of patients who presented early 
Table 2 Differences between patients who present with early and late colorectal cancer in Hospital Tuanku Ja'afar, Seremban during the period 2008-2012

\begin{tabular}{|c|c|c|c|c|}
\hline & Early $n=85(30.9 \%)$ & Late $\mathrm{n}=137(49.8 \%)$ & No Record n=53 (19.3\%) & $P$ value \\
\hline Female & $38(33.9)$ & $54(48.2)$ & $20(17.9)$ & \\
\hline Male & $47(28.8)$ & $83(50.9)$ & $33(20.2)$ & \\
\hline Race & & & & 0.711 \\
\hline Malays & $37(32.2)$ & $54(47.0)$ & $24(20.9)$ & \\
\hline Indians & $8(25.8)$ & $19(61.3)$ & $4(12.9)$ & \\
\hline Marital status & & & & 0.197 \\
\hline Married & $48(33.1)$ & $75(51.7)$ & $22(15.2)$ & \\
\hline Age & & & & 0.002 \\
\hline$<50$ & $11(25.6)$ & $31(72.1)$ & $1(2.3)$ & \\
\hline$\geq 50$ & $74(32.0)$ & $106(45.9)$ & $51(22.1)$ & \\
\hline \multicolumn{5}{|l|}{ Symptoms } \\
\hline Abdominal pain & $19(23.2)$ & $52(63.4)$ & $11(13.4)$ & 0.014 \\
\hline Intestinal obstruction & $11(22.9)$ & $32(66.7)$ & $5(10.4)$ & 0.007 \\
\hline Weight loss & $21(29.2)$ & $41(56.9)$ & $10(13.9)$ & 0.046 \\
\hline Blood in stools & $35(34.0)$ & $50(48.5)$ & $18(17.5)$ & 0.080 \\
\hline Rectum & $45(31.7)$ & $70(49.3)$ & $27(19.0)$ & \\
\hline
\end{tabular}

(stage I and II) compared to those who presented late (stage III and IV). There was no significant difference between men and women nor among the different ethnic groups in early or late presentation. However, age was a significant factor. Only $26 \%$ of those below the age of 50 years $(n=11 / 43)$ presented early $(\mathrm{P}=0.002)$. Patients with late cancer had significantly more abdominal pain, intestinal obstruction and weight loss on presentation. Patients with early cancer were likely to have blood in stools (37.8\%) and altered bowel habits (52.0\%).

\section{Survival rates}

The survival chart of colorectal cancer patients is shown in Figure 1. The overall 5-year survival rate was $46.5 \%$. Mean (95\% CI) survival time was $66.4(60.4,72.4)$ months, and median (95\% CI) survival for colorectal cancer was 53.0 (48.7, 57.3) months. The five-year survival rates of patients with stage I and II disease combined, stage III and stage IV patients were $67.9 \%, 50.5 \%$ and $12.8 \%$ respectively (Table 3). The five-year survival for those not staged was $30.2 \%$ suggesting that most of them were in stage III and IV. 


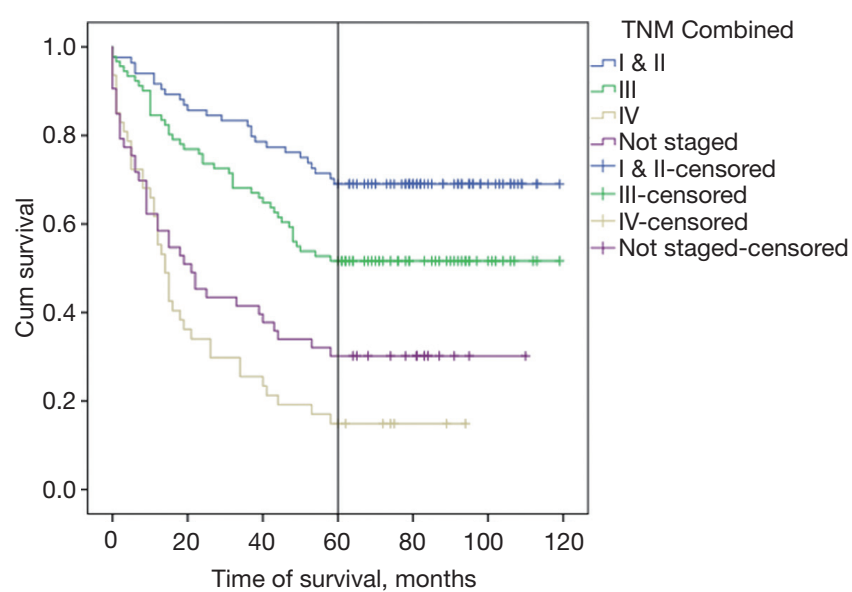

Figure 1 The Kaplan-Meier survival curve for colorectal cancer patients by stage, in Hospital Tuanku Ja'afar, Seremban, 20082012 .
There was a significant difference in the survival rate of colon cancer patients who were less than 62.5 years (the mean age for the cohort of patients) compared to patients aged 62.5 years and above $(\mathrm{P}=0.006)$ (Figure 2$)$.

There was no significant difference of survival rate of colorectal cancer patients who received elective surgery compared to patients receiving other treatments such as non-elective surgery, neoadjuvant therapy and palliative care $(\mathrm{P}=082)$ (Table 3).

From the multiple Cox regression model, predictors of 5 -year survival for colorectal cancer patients are age and staging (all $\mathrm{P}<0.05)$. The risk of colorectal cancer death was higher among stage IV (HR, 5.32; 95\% CI, 2.95 to 9.59), stage III (HR, 2.19; 95\% CI, 1.25 to 3.86), and non-staged patients (HR, 3.35; CI, 1.54 to 7.25 ). The hazard ratio for death in colorectal cancer patients increased by 1.004

Table 3 The 5-year survival rate according to different prognostic factors for 275 patients diagnosed with colorectal cancer during the period of 2008-2012 using Kaplan-Meier analysis and simple cox regression

\begin{tabular}{|c|c|c|c|c|c|}
\hline \multirow{2}{*}{ Variables } & \multicolumn{3}{|c|}{ Kaplan-Meier analysis } & \multicolumn{2}{|c|}{ Simple Cox regression } \\
\hline & $\mathrm{N}$ & The 5-year survival rate & $P$ value & Crude HR (95\% Cl) & $\mathrm{P}$ value \\
\hline \multicolumn{6}{|l|}{ Age (year) } \\
\hline$\geq 62.5$ & 157 & 38.9 & & & \\
\hline Sex & & & 0.891 & $1.023(0.736-1.423)$ & 0.892 \\
\hline Male & 163 & 44.8 & & & \\
\hline Race & & & 0.108 & $0.894(0.751-1.064)$ & 0.205 \\
\hline Chinese & 129 & 41.9 & & & \\
\hline India & 31 & 58.1 & & & \\
\hline Non-elective surgery & 80 & 45 & & & \\
\hline Missing & 76 & & & & \\
\hline Site of tumour & & & 0.935 & $0.992(0.843-1.167)$ & 0.921 \\
\hline Colon & 117 & 51.3 & & & \\
\hline Rectum & 142 & 45.1 & & & \\
\hline Staging & & & $<0.001$ & $1.585(1.375-1.827)$ & $<0.001$ \\
\hline$|\&| \mid$ & 84 & 67.9 & & & \\
\hline III & 91 & 50.5 & & & \\
\hline
\end{tabular}


years as the age increased by one year. No association was identified for race and type of treatment.

\section{Discussion}

The overall 5-year survival for colorectal cancer in this study $(46.5 \%)$ was similar to what was noted in the nationwide NCPR-CC report for Malaysia (48.7\%) for patients presenting between 2008-2009 (8). HTJS is the largest government hospital in Negeri Sembilan and offers surgery by colorectal-trained surgeons for the state, serving the lower income group. Public healthcare accounts for about $50 \%$ of health expenditure in Malaysia and covers about $70 \%$ of the population (4). The clinical characteristics

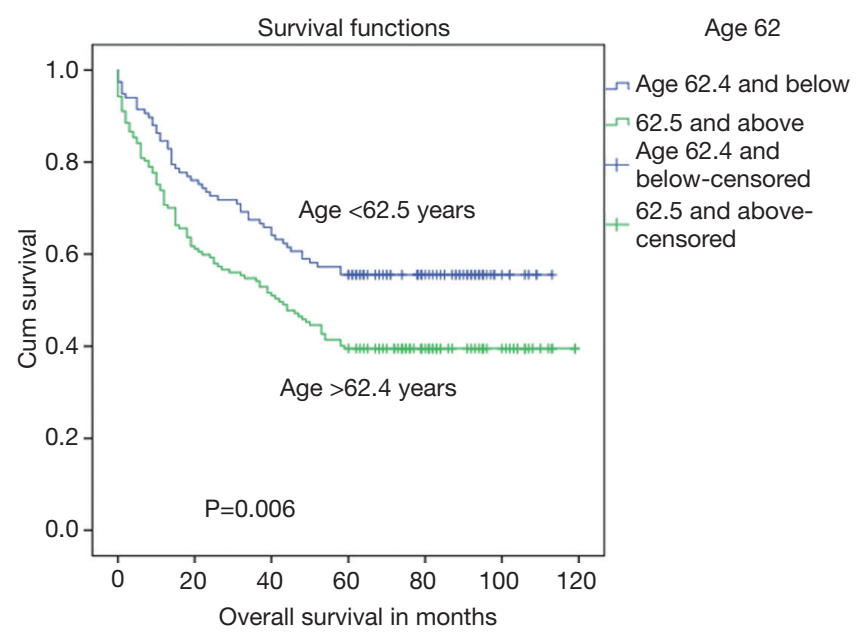

Figure 2 The Kaplan-Meier survival curve for colorectal cancer patients by age, in Hospital Tuanku Ja'afar, Seremban, 2008-2012. and predictors of survival of colorectal cancer in HTJS is of interest because it is applicable to other Ministry of Health hospitals which form the core of care for colorectal cancer in Malaysia (4).

A comparison with other Malaysian studies is given in Table 4. The survival rates by stage closely match most of these Malaysian studies but is lower than in developed Asian regions (such as Singapore and Taiwan). The highest overall reported 5-year survival rate in Malaysia was $60.5 \%$ in Kuala Lumpur for patients between 2000-2004 (12). The same study noted a $45.7 \% 5$-year survival rate for Sarawak. It should be noted that the Gross Domestic Product (GDP) per capita and monthly household income for Kuala Lumpur was almost twice that of Sarawak. Survival was also lower for every stage of CRC for Sarawak compared to Kuala Lumpur. Besides limited options for adjuvant treatment, there were no colorectal-trained surgeons at SGH and operations were done by general surgeons who were relatively more junior in terms of experience compared to UMMC (12). The GDP per capita of Negeri Sembilan in 2016 (RM 38,559) was lower than that of Kuala Lumpur (RM101,420) and almost similar to Sarawak (RM 44,333). It was also very similar to the overall GDP per capita of Malaysia (RM 38,887) in 2016 (17).

We found that the significant predictors of 5-year survival for colorectal cancer patients are age and stage of disease. Among these two predictors, staging was the strongest prognostic factor in both univariate and multivariate analyses. The highest hazard ratio (HR) was found to be in stage IV patients. This result was found to be consistent with established data. We did not find tumour site, race nor sex to be important predictors for survival. The Chinese appear

Table 4 Five-year survival rates for colorectal cancer in Malaysia and other countries by stage of disease

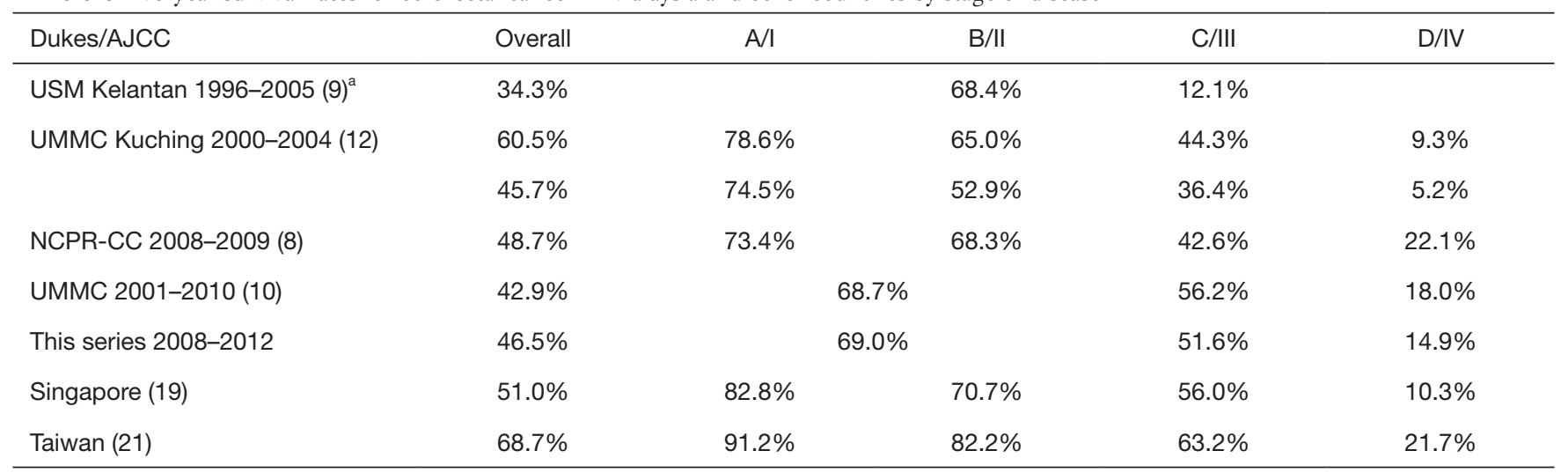

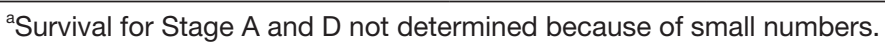


to have a lower rate of survival (41.9\%), which although not statistically significant has been previously noted for colon cancer alone (but not all colorectal cancer) (10). This could be because Chinese patients were older at presentation (mean age of Chinese was 66 years versus 59.3 for Malays and 58.7 for Indians, $\mathrm{P}<0.001$ ).

The most striking finding of this study is the high proportion of late colorectal cancer in HTJS. The survival curve of those not staged lies between that of stage III and IV and closer to stage IV, strongly suggesting they are late cancers. The proportion of patients presenting with stage I disease $(2.2 \%)$ is especially low compared to most other previously published studies in Malaysia $(7,10,18)$, the closest being a series from UKM (2.8\%) (11). The exception among these is Hassan et al. who noted a rate of $11.4 \%$ (8). None of the others reported a rate of Stage I disease above 7\% which fares poorly compared to regions in Asia such as Singapore (16.1\%) (19), Iran (17.5\%) (20) and Taiwan (21.9\%) (21).

The low survival observed for our stage II patients may partly be explained by the fact that $73.5 \%(61 / 83)$ of our stage I and II patients are in Stage IIb. Even in the United States Stage IIb is reported to have a 5 -year survival rate of $51-65 \%(22,23)$.

CRC patients who present below the age of 50 years are considered young and often a focused group, as screening is usually commenced for the population above that age. It is noteworthy that $15.6 \%$ of our patients fell into this category. Furthermore, these young patients presented late more often than not. That they do not have a poorer survival rate was a small consolation. This was probably due to older patients being less physically healthy overall.

In Malaysia, where just a generation ago CRC was not a disease commonly seen, awareness of the disease is a barrier to early detection of colorectal cancer (24-26) especially in the rural population where as high as a third of the population had no knowledge about warning signs and risk factors of CRC (27).

Increasing awareness of the gravity of late presentation of CRC is the key. This will need to be followed up by making screening more readily available. Reports to date show less than $2 \%$ of CRC patients have undergone a screening procedure $(24,26)$ and knowledge and practice of colorectal cancer screening among primary care physicians is low (28). Clinical practice guidelines for Malaysia recognizes the need for screening for CRC (29) but as yet there is no population screening programme. The cost effectiveness of pilot studies is in progress.

\section{Limitations}

The study was of a retrospective design, which relied largely on the data extracted from medical records. It was heavily dependent on accurate record keeping. Some data such as socioeconomic status, education level, marital status, occupation, co-morbidities, family history of malignancy, social lifestyle of patient, especially smoking and diet history were either insufficient or unavailable. Data verification was tedious as electronic records were often incomplete and hard copies in different places were shelved only up to 7 years, and subsequently destroyed. Coding errors of stage of disease were noted. However, this was not altered if it was based on accepted practice and imaging modalities available at the time. In particular CT findings of lung nodules interpreted as metastases (based on radiologist's report they may be malignant), when combined with survival data were found to be incorrect retrospectively. Similarly, the accuracy of coding the stage of CRC is open to error when based on laparotomy and current imaging techniques, which may under-stage disease because small deposits of tumours may be missed, a situation likely to occur in Stage IIB cases.

\section{Strengths}

There were opportunities to verify data because the study was based in the institution providing source data to the NCPR-CC, allowing records from the registry to be crossed checked for accuracy with admission summaries, histopathology and radiology department records.

\section{Conclusions}

In spite of having good surgical facilities, the 5 -year survival rate for colorectal cancer in Negeri Sembilan is $46.5 \%$. Patients under the age of 50 years present late more often, but do not result in poorer survival. Age and late presentation are two important predictors of poor outcome. Creating awareness will be helpful in managing colorectal cancer at an early stage.

\section{Acknowledgments}

The authors thank the Director General of Health, Malaysia for his permission to publish this article.

Funding: An internal funding grant was received for this 
student research project from the International Medical University.

\section{Footnote}

Conflicts of Interest: All authors have completed the ICMJE uniform disclosure form (available at http://dx.doi. org/10.21037/jgo.2020.02.04). The authors have no conflicts of interest to declare.

Etbical Statement: The authors are accountable for all aspects of the work in ensuring that questions related to the accuracy or integrity of any part of the work are appropriately investigated and resolved. Ethical clearance was obtained from the International Medical University Joint Committee and the National Medical Research and Ethics Committee. This study was registered under the National Medical Research Registry (NMRR-17-138036236 IIR).

Open Access Statement: This is an Open Access article distributed in accordance with the Creative Commons Attribution-NonCommercial-NoDerivs 4.0 International License (CC BY-NC-ND 4.0), which permits the noncommercial replication and distribution of the article with the strict proviso that no changes or edits are made and the original work is properly cited (including links to both the formal publication through the relevant DOI and the license). See: https://creativecommons.org/licenses/by-ncnd $/ 4.0 \%$.

\section{References}

1. Ferlay J, Soerjomataram I, Dikshit R, et al. Cancer incidence and mortality worldwide: sources, methods and major patterns in GLOBOCAN 2012. Int J Cancer 2015;136:E359-86.

2. Bray F, Ferlay J, Soerjomataram I, et al. Global cancer statistics 2018: GLOBOCAN estimates of incidence and mortality worldwide for 36 cancers in 185 countries. CA Cancer J Clin 2018;68:394-424.

3. Torre LA, Siegel RL, Ward EM, et al. Global Cancer Incidence and Mortality Rates and Trends--An Update. Cancer Epidemiol Biomarkers Prev 2016;25:16-27.

4. Veettil SK, Lim KG, Chaiyakunapruk N, et al. Colorectal cancer in Malaysia: Its burden and implications for a multiethnic country. Asian J Surg 2017;40:481-9.
5. Yusoff SN, Zulkifli Z. Rethinking of Old Age: The Emerging Challenge for Malaysia. IPEDR. V71. 13 [Internet]. 2014. Available online: http://www.ipedr.com/ vol71/013-ICCKS2014_S10011.pdf

6. Law CW, Roslani AC, Ng LLC. Treatment delay in rectal cancer. Med J Malaysia 2009;64:163-5.

7. Goh KL, Quek KF, Yeo GTS, et al. Colorectal cancer in Asians: a demographic and anatomic survey in Malaysian patients undergoing colonoscopy. Aliment Pharmacol Ther 2005;22:859-64.

8. Hassan MRA, Suan MAM, Soelar SA, et al. Survival Analysis and Prognostic Factors for Colorectal Cancer Patients in Malaysia. Asian Pac J Cancer Prev 2016;17:3575-81.

9. Ghazali AK, Musa KI, Naing NN, et al. Prognostic factors in patients with colorectal cancer at Hospital Universiti Sains Malaysia. Asian J Surg 2010;33:127-33.

10. Magaji BA, Moy FM, Roslani AC, et al. Survival rates and predictors of survival among colorectal cancer patients in a Malaysian tertiary hospital. BMC Cancer 2017;17:339.

11. Rashid MRA, Aziz AFA, Ahmad S, et al. Colorectal cancer patients in a tertiary referral centre in Malaysia: a five year follow-up review. Asian Pac J Cancer Prev 2009;10:1163-6.

12. Kong CK, Roslani AC, Law CW, et al. Impact of socioeconomic class on colorectal cancer patient outcomes in Kuala Lumpur and Kuching, Malaysia. Asian Pac J Cancer Prev 2010;11:969-74.

13. Lim KG. A review of colorectal cancer research in Malaysia. Med J Malaysia 2014;69 Suppl A:23-32.

14. World Health Organization. ICD-10 International Statistical Classification of Disease and Related Health Problem 10th Revision, Vol 3 (alphabetic index) 1994. Geneva: World Health Organization, 1994.

15. AJCC - 8th Edition Updates and Corrections [Internet]. [cited 2019 Mar 19]. Available online: https:// cancerstaging.org/references-tools/deskreferences/ pages/8eupdates.aspx

16. Bursac Z, Gauss CH, Williams DK, et al. Purposeful selection of variables in logistic regression. Source Code Biol Med 2008;3:17.

17. Department of Statistics Malaysia Official Portal [Internet]. [cited 2019 Jan 24]. Available online: https://www.dosm.gov.my/v1/index.php?r=column/ cthemeByCat\&cat=102\&bul_id=VS9Gckp1UUpKQUF WS1JHUnJZS2xzdz09\&menu_id=TE5CRUZCblh4ZTZ MODZIbmk2aWRRQT09

18. Singapore Cancer Registry Annual Registry Report 2015 
National Registry of Diseases Office (NRDO). Available online: https://www.nrdo.gov.sg/publications/cancer

19. Lee CH, Cheng SC, Tung HY, et al. The Risk Factors Affecting Survival in Colorectal Cancer in Taiwan. Iran J Public Health 2018;47:519-30.

20. Shah SA, Neoh HM, Rahim SSSA, et al. Spatial analysis of colorectal cancer cases in Kuala Lumpur. Asian Pac J Cancer Prev 2014;15:1149-54.

21. Zare-Bandamiri M, Khanjani N, Jahani Y, et al. Factors Affecting Survival in Patients with Colorectal Cancer in Shiraz, Iran. Asian Pac J Cancer Prev 2016;17:159-63.

22. Chu QD, Zhou M, Medeiros KL, et al. Poor survival in stage IIB/C (T4N0) compared to stage IIIA (T1-2 N1, T1N2a) colon cancer persists even after adjusting for adequate lymph nodes retrieved and receipt of adjuvant chemotherapy. BMC Cancer 2016;16:460.

23. Survival Rates for Colorectal Cancer, by Stage [Internet]. [cited 2018 Dec 3]. Available online: https://www.cancer. org/cancer/colon-rectal-cancer/detection-diagnosisstaging/survival-rates.html

24. Yusoff HM, Daud N, Noor NM, et al. Participation and

Cite this article as: Lim KG, Lee CS, Chin DHJ, Ooi YS, Veettil SK, Ching SM, Burud IAS, Zakaria J. Clinical characteristics and predictors of 5 -year survival among colorectal cancer patients in a tertiary hospital in Malaysia. J Gastrointest Oncol 2020;11(2):250-259. doi: 10.21037/ jgo.2020.02.04 barriers to colorectal cancer screening in Malaysia. Asian Pac J Cancer Prev 2012;13:3983-7.

25. Al-Naggar RA, Bobryshev YV. Knowledge of colorectal cancer screening among young Malaysians. Asian Pac J Cancer Prev 2013;14:1969-74.

26. Hilmi I, Hartono JL, Goh K. Negative perception in those at highest risk--potential challenges in colorectal cancer screening in an urban asian population. Asian Pac J Cancer Prev 2010;11:815-22.

27. Su TT, Goh JY, Tan J, et al. Level of colorectal cancer awareness: a cross sectional exploratory study among multi-ethnic rural population in Malaysia. BMC Cancer 2013;13:376.

28. Ooi CY, Hanafi NS, Liew SM. Knowledge and practice of colorectal cancer screening in an urban setting: crosssectional survey of primary care physicians in government clinics in Malaysia. Singapore Med J 2019;60:596-604.

29. Academy of Medicine of Malaysia - Clinical Practice Guidelines (CPGs) [Internet]. [cited $2019 \mathrm{Feb} 1]$. Available online: http://www.acadmed.org.my/index. cfm?\&menuid $=67$ 